\title{
The effects of viewing physical and relational aggression in the media: Evidence for a cross-over effect
}

\author{
Sarah M. Coyne \\ Brigham Young University - Provo \\ David A. Nelson \\ Brigham Young University - Provo, david_nelson@byu.edu \\ Frances Lawton \\ University of Central Lancashire \\ Shelly Haslam \\ University of Central Lancashire \\ Eqlley'Rbbisand additional works at: https://scholarsarchive.byu.edu/facpub \\ onipersityfafeentral sancashire Behavioral Sciences Commons
}

\section{Brigipal Payelicationicitationors}

Coyne, S. M., Nelson, D. A., *Lawton, F., *Haslam, S., *Rooney, L., *Titterington, L., *Trainor, H., *Remnant, J., \& * Ogunlaja, L. (2008). The effects of viewing physical and relational aggression in the media: Evidence for across-over effect. Journal of Experimental Social Psychology, 44, 1551-1554.

\section{BYU ScholarsArchive Citation}

Coyne, Sarah M.; Nelson, David A.; Lawton, Frances; Haslam, Shelly; Rooney, Lucy; Titterington, Leigh; Trainor, Hannah; Remnant, Jack; and Ogunlaja, Leah, "The effects of viewing physical and relational aggression in the media: Evidence for a cross-over effect" (2008). Faculty Publications. 4561. https://scholarsarchive.byu.edu/facpub/4561

This Peer-Reviewed Article is brought to you for free and open access by BYU ScholarsArchive. It has been accepted for inclusion in Faculty Publications by an authorized administrator of BYU ScholarsArchive. For more information, please contact ellen_amatangelo@byu.edu. 


\section{Authors}

Sarah M. Coyne, David A. Nelson, Frances Lawton, Shelly Haslam, Lucy Rooney, Leigh Titterington, Hannah Trainor, Jack Remnant, and Leah Ogunlaja 


\title{
The effects of viewing physical and relational aggression in the media: Evidence for a cross-over effect
}

\author{
Sarah M. Coyne ${ }^{\mathrm{a}, *}$, David A. Nelson ${ }^{\mathrm{a}}$, Frances Lawton ${ }^{\mathrm{b}}$, Shelly Haslam ${ }^{\mathrm{b}}$, Lucy Rooney ${ }^{\mathrm{b}}$, Leigh Titterington ${ }^{\mathrm{b}}$, \\ Hannah Trainor ${ }^{\mathrm{b}}$, Jack Remnant ${ }^{\mathrm{b}}$, Leah Ogunlaja ${ }^{\mathrm{b}}$ \\ a Brigham Young University, School of Family Life, JFSB 2087, Provo, UT 84602, USA \\ ${ }^{\mathrm{b}}$ University of Central Lancashire Department of Psychology, Preston, UK
}

\section{A R T I C L E I N F O}

\section{Article history:}

Received 16 June 2008

Revised 21 June 2008

Available online 18 July 2008

\section{Keywords:}

Relational aggression

Indirect aggression

Physical aggression

Media

Violence

\begin{abstract}
A B S T R A C T
Research has shown that viewing violence in the media can have a profound impact on aggressive thoughts and behaviors. However, the impact of viewing relational aggression in the media has rarely been examined. This paper presents the results of an experimental study that examines the impact of viewing relational and physical aggression in the media on subsequent aggression. In this study, adult females were shown video clips containing no-aggression, relational aggression, or physical aggression. Their aggressive behavior was measured through the use of a competitive reaction time task (physical aggression) and evaluations of a confederate of the experiment (relational aggression). As a whole, participants viewing either relational or physical aggression behaved similarly. Specifically, participants who viewed either type of aggression were subsequently more physically and relationally aggressive than those who viewed the non-aggressive clip. The results show evidence for a generalization effect of viewing media aggression, in that viewing one form of aggression can influence the manifestation of other forms. This is the first study to show that viewing relational aggression in the media can increase subsequent physical aggression. Implications for parents, media producers, and policy makers are discussed.
\end{abstract}

(c) 2008 Elsevier Inc. All rights reserved.

\section{Introduction}

In recent years, there has been increasing interest in the manner in which individuals manipulate relationships to intentionally hurt another individual. Several groups of researchers have separately referred to these behaviors as indirect aggression (e.g., Lagerspetz, Björkqvist, \& Peltonen, 1988), relational aggression (e.g., Crick \& Grotpeter, 1995) or social aggression (e.g., Galen \& Underwood, 1997). On the whole, these terms are little different (Archer \& Coyne, 2005; Coyne, Archer, \& Eslea, 2006). The main distinction appears to be the amount of focus on indirect (e.g., spreading rumors) and/or direct (e.g., threatening to withdraw friendship) forms of relationship manipulation, both of which are captured by the relational aggression construct (Crick et al., 1999; Nelson, Springer, Nelson, \& Bean, 2008). Our review of existing studies delineates relational manipulation by the term used in each study.

Definitions of aggression are important as incomplete definitions limit the scope of the behaviors examined. Media violence research has focused on portrayals of physical violence as they relate to subsequent physical aggression (e.g., Bushman \& Anderson, 2001). However, physical aggression is not the only form of aggres-

\footnotetext{
* Corresponding author.

E-mail address: smcoyne@byu.edu (S.M. Coyne).
}

sion portrayed on television. Relational aggression, in both indirect and direct forms, is also portrayed frequently (Coyne, 2004). Among TV programs in the UK (Coyne \& Archer, 2004), more than $90 \%$ show some form of indirect aggression, which is also likely to be portrayed as justified, rewarded, and performed by attractive characters. Accordingly, individuals may be learning to be relationally aggressive at least in part through such media.

Limited evidence shows that viewing indirect aggression in the media can increase subsequent aggression. Coyne, Archer, and Eslea (2004) showed videos to adolescents that portrayed either indirect or physical aggression or no-aggression at all. When given an opportunity to indirectly (relationally) aggress against an obnoxious confederate of the experiment, participants who viewed either form of aggression were more aggressive, at similar levels, than peers who viewed the no-aggression videos. This was somewhat surprising, as it was expected that viewing indirect aggression would be the primary context for indirectly (relationally) aggressive action toward the confederate. Rather, the study suggested a cross-over effect: those participants who viewed physical aggression were also more relationally aggressive.

This cross-over effect has also been found in other studies. First, females who viewed excessive physical violence on television as children were more indirectly aggressive as adults (Huesmann, Moise, Podolski, \& Eron, 2003). Ostrov, Gentile, and Crick (2006) 
also found that children who viewed high amounts of televised physical violence were subsequently more relationally aggressive. This cross-over effect helps answer critics of media violence research, who claim that violent depictions are relatively harmless, given that so many people view media violence but so few commit violent crimes. It may be that, for most individuals, the expressed aggression actually takes the form of a whispered rumor, or a furtive glance. This is aggression that hardly seems newsworthy or even noticeable, particularly in light of how often it tends to occur.

The alternative cross-over effect (i.e., relationally aggressive depictions leading to subsequent enactment of physical aggression) has not been tested in any study to date. It is therefore unclear if the cross-over effect is specific to depictions of physical violence or generalizes to relationally aggressive media depictions as well. One way to interpret the mechanisms underlying a crossover effect is suggested by the General Aggression Model (GAM; Anderson \& Bushman, 2002), which states that cognitive scripts in memory help guide and interpret human behavior. After viewing violence, "aggressive" scripts are activated, increasing the likelihood of subsequent aggressive behavior. Whether a person acts on these aggressive scripts is also dependent on personal characteristics, such as past experiences, level of arousal, and the situational context (see also Gentile \& Sesma, 2003).

In summary, this study adds to existing literature by including depictions of both physical and relational aggression and the opportunity for participants to enact both physical and relational aggression following media exposure. Based on the GAM, we predicted that specific and generalized aggressive behavior would occur after viewing physical and relational aggression in the media.

\section{Methods}

Pilot study: videos

A pilot study was conducted to ensure that the videos did not differ in excitement level. Twenty-two participants viewed a total of 10 film clips (9-15 min in length), involving physical, relational, or no-aggression. All films were produced in the previous five years and had female characters as the protagonist and antagonist (if present).

Physiological measurements (blood pressure, heart rate, and galvanic skin response) were taken just before, during, and after each clip to assess current excitement levels. Participants also completed a questionnaire asking them to rate the clip (on an 11-point Likert scale) on 13 factors measuring excitatory variables (e.g., exciting), aggressive content (e.g., violence), and other variables (e.g., realistic, enjoyable).

A series of repeated measures ANOVAs were conducted to assess which films were most appropriate for the current study. The physical aggression clip chosen was from Kill Bill (Weinstein, Weinstein, Bender, \& Tarantino, 2004; rated R), and contained a graphic, violent fight between two women. The relational aggression clip chosen was from Mean Girls (Messick, Michaels, Waters, \& Fey, 2004; rated PG-13) and portrayed the fighting that occurs in "girl world," including relational manipulation and social exclusion. The control clip was from What Lies Beneath (Zemeckis \& Gregg, 2000; rated PG-13), and showed a woman having a séance to communicate with a ghost.

Analyses revealed that the films produced similar excitement, as shown by physiological ratings (BP, HR, and GSR) and the excitatory questionnaire items (all ANOVA results were non-significant). When aggressive content was analyzed, Kill Bill was rated as significantly more physically violent than the other two clips
$(F(2,42)=3581.90, p<.001)$, while Mean Girls was rated as more relationally aggressive than the other two $(F(2,42)=42.28$, $p<.001)$. In addition, all three clips were rated similarly on all other variables measured, except for two which are controlled for in subsequent analyses. In particular, What Lies Beneath was rated as more frightening than the other two $(F(2,42)=47.31$, $p<.001)$, and Mean Girls was rated as more humorous $(F(2,42)=$ $19.31, p<.001)$.

\section{Main study}

\section{Participants}

The main study consisted of a total of 60 participants; however, seven participants were omitted from the study. Three expressed suspicion regarding the cover story, three had substantial missing data, and one was an extreme outlier whose data was nonsensical. All were female undergraduate university students (mean age $=23.13$ ). There were 17 participants in the physical aggression condition, 18 in the relational condition, and 18 in the no-aggression condition, yielding a total of 53 participants.

\section{Procedure}

Participants were first told a cover story-that the female experimenter was interested in examining how television/film portrays female heroines throughout history. They were told that they would view a $10-15$ min video clip from a particular time period (determined randomly) and fill out an attitude questionnaire later.

The participant then completed the Richardson Conflict Response Questionnaire (RCRQ) which measured prior indirect (relational) and direct aggressive behavior (Richardson \& Green, 2003). Reliability was acceptable for both indirect $(\alpha=.80)$ and direct aggression $(\alpha=.83)$. The purpose of this questionnaire is to control for prior aggressiveness in subsequent analyses.

Participants next viewed one of the three videos. After this, participants completed a questionnaire asking for biographical information (e.g., gender, age, TV viewing habits) and their thoughts on whether the portrayal of females on television had changed throughout history (to support the cover story). Participants were then led to believe that the study was complete. The experimenter mentioned that another study was taking place next door and asked if they might participate. When leaving the lab room, each participant was met by a female confederate of the experiment who was posing as the experimenter of the other study.

The confederate led the participant through a three-minute puzzle completion task, involving 10 of the most advanced of Raven, Court, and Raven's (1983) matrices, ostensibly analyzing speed of completion. During the task, the confederate engaged in purposeful antagonistic behavior, such as pacing with a stopwatch, sighing loudly, and making comments such as, "Hurry please!" When the time elapsed, the confederate asked if the participant was confident that she answered all questions correctly. All participants expressed some uneasiness with their performance. The confederate then sighed loudly and said, "Great! This is really going to screw things up!" The purpose of the antagonistic behavior was to encourage animosity towards the confederate, potentially inducing the participant to behave aggressively.

Participants then took part in a competitive reaction time test (CRT), a paradigm that has been often used to measure physical aggression after viewing televised violence (e.g., Taylor, 1967). The confederate explained the task fully, and then left the room, ostensibly to connect via another computer in a separate area. Essentially, this task consists of 25 trials where participants choose from 10 noise levels (ranging from $0-105 \mathrm{~dB}$ ) and 10 noise durations (ranging from $0-5 \mathrm{~s}$ ) to be administered to an opponent (the confederate) should they show a slower reaction time in a button-pushing contest. Mean scores were calculated for noise level 
and duration based on the levels set by each participant; accordingly each participant could have a mean score in the range of 0-10. See Bushman (1995) for a full description of the task.

Participants then completed evaluation forms for both experimenters (counterbalanced), supposedly to be used as part of a hiring process. The evaluation (10 questions) assessed various dimensions (e.g., professionalism, skill level, effectiveness) using a 10-point Likert-type scale (with higher scores reflecting greater competence). This paradigm has been called the laboratory equivalent of spreading rumors (Buss, 1961) and has been used successfully in other studies (e.g. Bushman \& Anderson, 1998; Coyne et al., 2004). Finally, participants were fully debriefed.

The above procedure parallels the experimental study conducted by Coyne et al. (2004), though it differs in a number of significant ways. Most important, the measure of physical aggression (using the CRT) was added so the cross-over effect of relationally aggressive media and subsequent physical aggression could be tested. Additionally, every aspect of the experiment involved females, making all elements of the study gender-constant. Finally, this study utilized popular movies as opposed to fabricated videos.

\section{Results}

Table 1 shows the estimated marginal means and standard errors for each condition on subsequent physical and relational aggression. A series of ANCOVAs were conducted for type of video viewed on two types of physical aggression measurements (loudness and duration), and two measures of relational aggression (evaluation of the confederate and the experimenter). The participant's prior physical and relational aggression (based on the RCRQ) were entered as covariates, as were the amount of TV viewed weekly, and ratings of how frightening and humorous each clip was.

For the physical aggression measurements, a significant effect was found for loudness, $F(2,45)=8.09, p<.001, \eta^{2}=.26$, and duration of the noise blasts, $F(2,45)=3.83, p<.05, \eta^{2}=.15$. For loudness, planned comparisons revealed that participants who viewed the physical aggression, $p<.001, d=1.27$, or the relational aggression video, $p<.001, d=1.09$, gave significantly louder noise blasts than those who viewed the no-aggression video. Moreover, there was no difference for the loudness of the blasts, $p=1.00$, $d=.16$, between viewers of the physical and relational aggression videos. In regard to duration, participants viewing the physical, $p<.05, d=.83$, or relational aggression video, $p<.01, d=.77$, gave significantly longer noise blasts than those viewing the no-aggression video (with no difference between viewers of the physical and relational aggression videos, $p=.91, d=.08$ ).

For relational aggression, the ANCOVAs revealed a significant effect for aggression against the confederate, $F(2,45)=3.21$, $p<.05, \eta^{2}=.13$, but not against the experimenter, $F(2,45)=1.98$,

Table 1

Estimated marginal means (and standard errors) for video viewed for physical, relational, and no-aggression measures

\begin{tabular}{llcc}
\hline & \multicolumn{3}{c}{ Video viewed } \\
\cline { 2 - 4 } & $\begin{array}{c}\text { Physical } \\
\text { aggression }\end{array}$ & $\begin{array}{c}\text { Relational } \\
\text { aggression }\end{array}$ & $\begin{array}{c}\text { No- } \\
\text { aggression }\end{array}$ \\
\hline $\begin{array}{l}\text { Physical aggression } \\
\text { Loudness }\end{array}$ & $6.11(.43)$ & $5.82(.42)$ & $3.97(.40)$ \\
$\begin{array}{l}\text { Duration } \\
\text { Relational aggression }\end{array}$ & $5.37(.43)$ & $5.23(.43)$ & $3.91(.40)$ \\
$\begin{array}{l}\text { Against the confederate } \\
\text { Against the experimenter }\end{array}$ & $3.50(.25)$ & $3.57(.24)$ & $4.26(.23)$ \\
\hline
\end{tabular}

* Higher scores indicate heightened aggression.

* Lower scores indicate heightened aggression. $p<.05, \eta^{2}=.05$. Planned comparisons revealed that participants who viewed the physical, $p<.01, d=.78$, or the relational aggression video, $p<.05, d=.71$, gave significantly harsher evaluations of the confederate than those viewing the no-aggression video. As for the physical aggression variables, there was no significant difference between participants who viewed the physical aggression and relational aggression videos, $p=.88, d=.07$.

\section{Discussion}

As a whole, we found some evidence of the generalized effects of viewing aggression in the media. This research therefore extends the general aggression model to incorporate both general and specific scripts as routes to the likelihood of an aggressive outcome (Anderson \& Bushman, 2002). Viewing aggression in the media may increase similar behavior in real life or, alternatively, forms of aggressive behavior that are different than the aggression portrayed. This study focused on short term effects; accordingly, long term studies may show more specificity of aggression effects.

Our results support a large body of research that shows that viewing physical violence in the media can increase subsequent physical aggression (e.g., Bushman \& Anderson, 2001). However, we also found that participants in the physical violent media condition were also more relationally aggressive towards the confederate, as compared to those who viewed no-aggression. Thus, viewing physical aggression in the media can generalize to other forms of aggression in real life. As noted earlier, media critics have suggested that media violence has little impact on individuals within the normative range. Our results suggest that viewing physical violence in the media can generalize to relational aggression. Therefore, viewing violence in the media can lead to more aggression, just perhaps not the exact form that was witnessed on the movie screen.

Participants who viewed relational aggression in the media were also more relationally aggressive. This supports previous work by Coyne and colleagues (2004, 2005), which showed that viewing relational aggression on television can have an impact on subsequent relational aggression in real life. Additionally, we found that those participants who viewed relational aggression were also subsequently more physically aggressive against the confederate of the experiment.

To our knowledge, this is the first study to find that viewing relational aggression in the media can increase subsequent physical violence. Currently, media watchdogs, parents, and politicians are focused on the effects of viewing physical violence in the media. However, our results suggest that they also should focus on relational aggression in the media as well, given its potential impact on both subsequent relational aggression and physical violence. It is possible that programs with low physical violence may still increase subsequent aggression in viewers if the aggression portrayed is more subtle and indirect and consequently escapes the scrutiny of parents, ratings board, and other regulatory bodies. We would suggest that these individuals look closely at all forms of aggressive behavior portrayed on television and in films. Whether content warnings are administered will be dependent on how the aggression is portrayed; however, our results suggest that relational aggression in the media should no longer be overlooked.

\section{References}

Anderson, C. A., \& Bushman, B. J. (2002). Human aggression. Annual Review of Psychology, 53, 27-51.

Archer, J., \& Coyne, S. M. (2005). An integrated review of indirect, relational, and social aggression. Personality and Social Psychology Review, 9, 212-230. 
Bushman, B. J. (1995). Moderating role of trait aggressiveness in the effects of violent media on aggression. Journal of Personality and Social Psychology, 69, 950-960.

Bushman, B. J., \& Anderson, C. A. (1998). Methodology in the study of aggression: Integrating experimental and nonexperimental findings. In R. G. Geen \& E. Donnerstein (Eds.). Human aggression: Theories, research, and implications for social policy (pp. 167-202). San Diego, CA: Academic Press.

Bushman, B. J., \& Anderson, C. (2001). Media violence and the American public. American Psychologist, 56, 477-489.

Buss, A. (1961). The psychology of aggression. New York: John Wiley \& Sons.

Coyne, S. M. (2004). Indirect aggression on screen: A hidden problem? The Psychologist, 17, 688-691.

Coyne, S. M., \& Archer, J. (2004). Indirect aggression in the media: A content analysis of British television programs. Aggressive Behavior, 30, 254-271.

Coyne, S. M., \& Archer, J. (2005). The relationship between indirect and physical aggression on television and in real life. Social Development, 14, 324-338.

Coyne, S. M., Archer, J., \& Eslea, M. (2004). Cruel intentions on television and in real life: Can viewing indirect aggression increase viewers' subsequent indirect aggression? Journal of Experimental Child Psychology, 88, 234-253.

Coyne, S. M., Archer, J., \& Eslea, M. (2006). "We're not friends anymore! Unless..." The frequency and harmfulness of indirect, relational, and social aggression. Aggressive Behavior, 32, 294-307.

Crick, N. R., \& Grotpeter, J. K. (1995). Relational aggression, gender, and socialpsychological adjustment. Child Development, 66, 710-722.

Crick, N. R., Werner, N. E., Casas, J. F., O’Brien, K. M., Nelson, D. A., Grotpeter, J. K., et al. (1999). Childhood aggression and gender: A new look at an old problem. In D. Bernstein (Ed.), Volume 45 of the Nebraska symposium on motivation: Gender and motivation (pp. 75-141). Lincoln: University of Nebraska Press.

Galen, B. R., \& Underwood, M. K. (1997). A developmental investigation of social aggression among children. Developmental Psychology, 33, 589-600.
Gentile, D. A., \& Sesma, A. (2003). Developmental approaches to understanding media effects on individuals. In D. A. Gentile (Ed.), Media violence and children (pp. 19-38). Westport, CT: Praeger.

Huesmann, L. R., Moise, J., Podolski, C., \& Eron, L. (2003). Longitudinal relations between children's exposure to television violence and their later aggressive and violent behavior in young adulthood: 1977-1992. Developmental Psychology, 39, 201-221.

Lagerspetz, K., Björkqvist, K., \& Peltonen, T. (1988). Is indirect aggression typical of females? Gender differences in aggressiveness in 11- to 12-year old children. Aggressive Behavior, 14, 403-414.

Messick, J., Michaels, L. (Producers), Waters, M. (Director), \& Fey, T. (Writer). (2004) Mean girls [Motion picture]. United States: Paramount Pictures.

Nelson, D. A., Springer, M. M., Nelson, L. J., \& Bean, N. H. (2008). Normative beliefs regarding aggression in emerging adulthood. Social Development, 17, 638-660.

Ostrov, J. M. Gentile, D. A. \& Crick, N. R. (2006). Media exposure, aggression, and prosocial behavior during early childhood: A longitudinal study. Social Development, 15, 612-627.

Raven, J. C., Court, J. H., \& Raven, J. (1983). Standard progressive matrices. London: Lewis \& Co.

Richardson, D. S., \& Green, L. R. (2003). Defining direct and relational aggression: The Richardson conflict response questionnaire. International Review of Socia Psychology, 16, 11-30.

Taylor, S. P. (1967). Aggressive behavior and physiological arousal as a function of provocation and the tendency to inhibit aggression. Journal of Personality, 35, 297-310.

Weinstein, B., Weinstein H., Bender, L. (Producers), Tarantino, Q. (Director/Writer) (2004). Kill bill: Vol. 1 [Motion picture]. United States: Miramax Films.

Zemeckis, R. (Producer/Director), \& Gregg, C. (Writer). (2000). What lies beneath [Motion picture]. United States: DreamWorks SKG/Twentieth Century Fox. 